\title{
Complete genome sequence analysis of the peanut pathogen Ralstonia solanacearum strain Rs-P.362200
}

\author{
Kun Chen ${ }^{1+}$, Lihui Wang ${ }^{1+}$, Hua Chen ${ }^{1,2}$, Chong Zhang ${ }^{1,2}$, Shanshan Wang ${ }^{1}$, Panpan Chu', Shaokang Li',
} Huiwen Fu', Tao Sun ${ }^{1}$, Menghan Liu', Qiang Yang ${ }^{1}$, Huasong Zou ${ }^{1}$ and Weijian Zhuang ${ }^{1} 2^{*}$

\begin{abstract}
Background: Bacterial wilt caused by Ralstonia solanacearum species complex is an important soil-borne disease worldwide that affects more than 450 plant species, including peanut, leading to great yield and quality losses. However, there are no effective measures to control bacterial wilt. The reason is the lack of research on the pathogenic mechanism of bacterial wilt.

Results: Here, we report the complete genome of a toxic Ralstonia solanacearum species complex strain, RsP.362200, a peanut pathogen, with a total genome size of $5.86 \mathrm{Mb}$, encoding 5056 genes and the average $\mathrm{G}+\mathrm{C}$ content of 67\%. Among the coding genes, 75 type III effector proteins and 12 pseudogenes were predicted. Phylogenetic analysis of 41 strains including Rs-P.362200 shows that genetic distance mainly depended on geographic origins then phylotypes and host species, which associated with the complexity of the strain. The distribution and numbers of effectors and other virulence factors changed among different strains. Comparative genomic analysis showed that 29 families of 113 genes were unique to this strain compared with the other four pathogenic strains. Through the analysis of specific genes, two homologous genes (gene ID: 2_657 and 3_83), encoding virulence protein (such as RipP1) may be associated with the host range of the Rs-P.362200 strain. It was found that the bacteria contained 30 pathogenicity islands and 6 prophages containing 378 genes, 7 effectors and 363 genes, 8 effectors, respectively, which may be related to the mechanism of horizontal gene transfer and pathogenicity evaluation. Although the hosts of HA4-1 and Rs-P.362200 strains are the same, they have specific genes to their own genomes. The number of genomic islands and prophages in HA4-1 genome is more than that in Rs-P.36220, indicating a rapid change of the bacterial wilt pathogens.
\end{abstract}

Conclusion: The complete genome sequence analysis of peanut bacterial wilt pathogen enhanced the information of $R$. solanacearum genome. This research lays a theoretical foundation for future research on the interaction between Ralstonia solanacearum and peanut.

Keywords: Ralstonia solanacearum, Peanut, Genome, Effector, Pathogenicity island, Prophage

\footnotetext{
*Correspondence: weijianz1@163.com

${ }^{\dagger}$ Kun Chen and Lihui Wang contributed equally to this work.

${ }^{1}$ College of Plant Protection, Fujian Agriculture and Forestry University,

Fuzhou 350002, Fujian, China

${ }^{2}$ College of Agronomy, Fujian Agriculture and Forestry University, Fuzhou

350002, Fujian, China
}

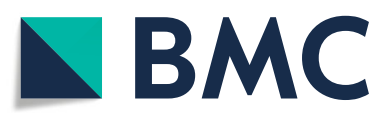

(c) The Author(s). 2021 Open Access This article is licensed under a Creative Commons Attribution 4.0 International License, which permits use, sharing, adaptation, distribution and reproduction in any medium or format, as long as you give appropriate credit to the original author(s) and the source, provide a link to the Creative Commons licence, and indicate if changes were made. The images or other third party material in this article are included in the article's Creative Commons licence, unless indicated otherwise in a credit line to the material. If material is not included in the article's Creative Commons licence and your intended use is not permitted by statutory regulation or exceeds the permitted use, you will need to obtain permission directly from the copyright holder. To view a copy of this licence, visit http://creativecommons.org/licenses/by/4.0/ The Creative Commons Public Domain Dedication waiver (http://creativecommons.org/publicdomain/zero/1.0/) applies to the data made available in this article, unless otherwise stated in a credit line to the data. 


\section{Background}

Ralstonia solanacearum ( $R$. solanacearum) is a Gramnegative bacterium, Burkolderiaceae (beta-proteobacteria) with a cell length of $0.5-1.5 \mu \mathrm{m}$ [1]. R.solanacearum is also considered to be Ralstonia solanacearum species complex (RSSC) due to the diversity of its genetic group. RSSC can survive in the soil for a long time, and once it can break through the plant defense line, it will enter the vascular bundle and multiply and cause the plant to die, thus returning to the soil again to prepare for the next transmission [2]. In the environment of laboratory aseptic water, $R$. solanacearum can survive for more than 4 years without weakening its pathogenicity, and it can survive for several years without any nutrients [3]. This phenomenon is extremely rare at present. It can be seen that the viability of $R$. solanacearum is very strong. It may also be one of the reasons why RSSC can spread widely in the world. RSSC can be divided into four phylotypes corresponding to geographical locations: Asian (phylotype I), American (phylotype II), African (phylotype III) and Indonesian (phylotype IV) [4]. Each phylotype can be subdivided into different sequevars, which may include different strains showing similar pathogenicity or a similar geographic origin [5]. In 2016, after Prior et al. added the relevant data of proteome and metabolic group to the original classification, RSSC were divided into three species: the first species (composed of phylotype I and phylotype III), the second species (composed of phylotype IIA and phylotype IIB), and the third species phylotype IV [6]. At present, this classification method is widely used by most researchers.

RSSC has been rated as the second most important plant pathogenic microorganism in the world, and it has also become a model bacteria for the study of plantpathogenic microorganism interaction [7]. Bacterial wilt caused by RSSC is one of the most extensive bacterial diseases in the world and can infect more than 450 species of plants in 54 families [8, 9]. Its hosts include not only dicotyledonous herbs such as Solanaceae and Leguminosae but also dicotyledonous woody plants such as mulberry, eucalyptus and Casuarina equisetifolia and monocotyledonous plants such as banana and ginger [10]. Bacterial wilt is an important disease that restricts peanut production in China and many Southeast Asian countries, and ranks first among several bacterial diseases of peanuts [11]. Bacterial wilt disease caused by the $R$. solanacearum Rs-P.362200 strain is a devastating disease in Chinese peanut production that can cause yield losses of up to $50-100 \%[12,13]$.

The pathogenicity of $R$. solanacearum is closely related to its virulence factors. In a nutritious environment, $R$. solanacearum synthesizes extracellular polysaccharides
(EPS) to block vascular bundles and hinder water transport, resulting in the death of host plants [14]. In addition to EPS, $R$. solanacearum exhibits many other virulence factors, such as effectors, type 4 fimbriae and polycarboxylate siderophore staphyloferrin $B$ $[15,16]$. Type III effector proteins (T3Es) account for a considerable fraction of the many virulence factors, and current research on these proteins is more extensive than that on other virulence factors [17]. $R$. solanacearum uses syringe-like type III secretion system to inject T3Es into plant cells, interfering with the life activities of the host. Some T3Es of $R$. solanacearum play a decisive role in the pathogenic process and are therefore referred to as toxic proteins. A few T3Es can be recognized by plant resistance gene products and stimulate resistant plants to produce a hypersensitive response (HR); these proteins are therefore referred to as avirulent proteins (Avr) [18].

The genomes of microorganisms are relatively small, and with the development of modern sequencing technology, more and more microbial genomes have been sequenced $[19,20]$. The sequencing of the whole genome of $R$. solanacearum could provide a theoretical basis for the study of its pathogenic mechanism and gene regulatory network. Since the sequencing of the GMI1000 strain in 2002 [21], an increasing number of strains have been sequenced. To date, the genome assemblies and annotations of $164 R$. solanacearum strains have been released in the NCBI database (https://www.ncbi.nlm.nih.gov/genome/browse/ \#!/prokaryotes/490/). HA4-1 is the first strain of $R$. solanacearum isolated from peanut and sequenced in 2019 [17]. Although increasing numbers of strains have been sequenced, more genomic sequences are still needed to fully analyze the species. Strains from different regions and different host sources vary greatly in their host range, pathogenicity, biotype, serotype and other bacteriological characteristics [22].

In the present study, we sequenced the whole genome of the Rs-P.362200 strain. The host-specific candidate genes and the evolutionary relationships of the strain were determined via comparative genomics and evolutionary analysis.

\section{Results}

\section{Genome sequencing, assembly and annotations}

To understand the interaction mechanism of RsP.362200 with peanut from the pathogen perspective, single-molecule real-time sequencing (SMRT) on the PacBio RS II platform was used to sequence the genome of Rs-P.362200. A total of $1.09 \mathrm{~Gb}$ of clean data were generated that covered 186 folds of the whole genome size. By following the MinHash Alignment Process (MHAP) [23, 24] workflow, the clean data from the 
Table 1 Results of genome assembly

\begin{tabular}{ll}
\hline Label & Size (bp) \\
\hline Chromosome & $3,721,710$ \\
Megaplasmid & $2,034,020$ \\
Small Plasmid & 101,780 \\
Total & $5,857,510$ \\
\hline
\end{tabular}

PacBio RS II platform were assembled into three scaffolds (corresponding to 1 chromosome, 1 megaplasmid and 1 small plasmid) of approximately $3.72 \mathrm{Mb}, 2.03 \mathrm{Mb}$, and $101 \mathrm{~kb}$, respectively (Table 1, Fig. 1). The sequences coverage depth of these scaffolds was at least $100 \mathrm{X}$ throughout the genome with average coverage from 130X 215X. The mean confidence of these scaffolds was close to QV50 (Supplementary 1), thereby we got a complete genome sequences.

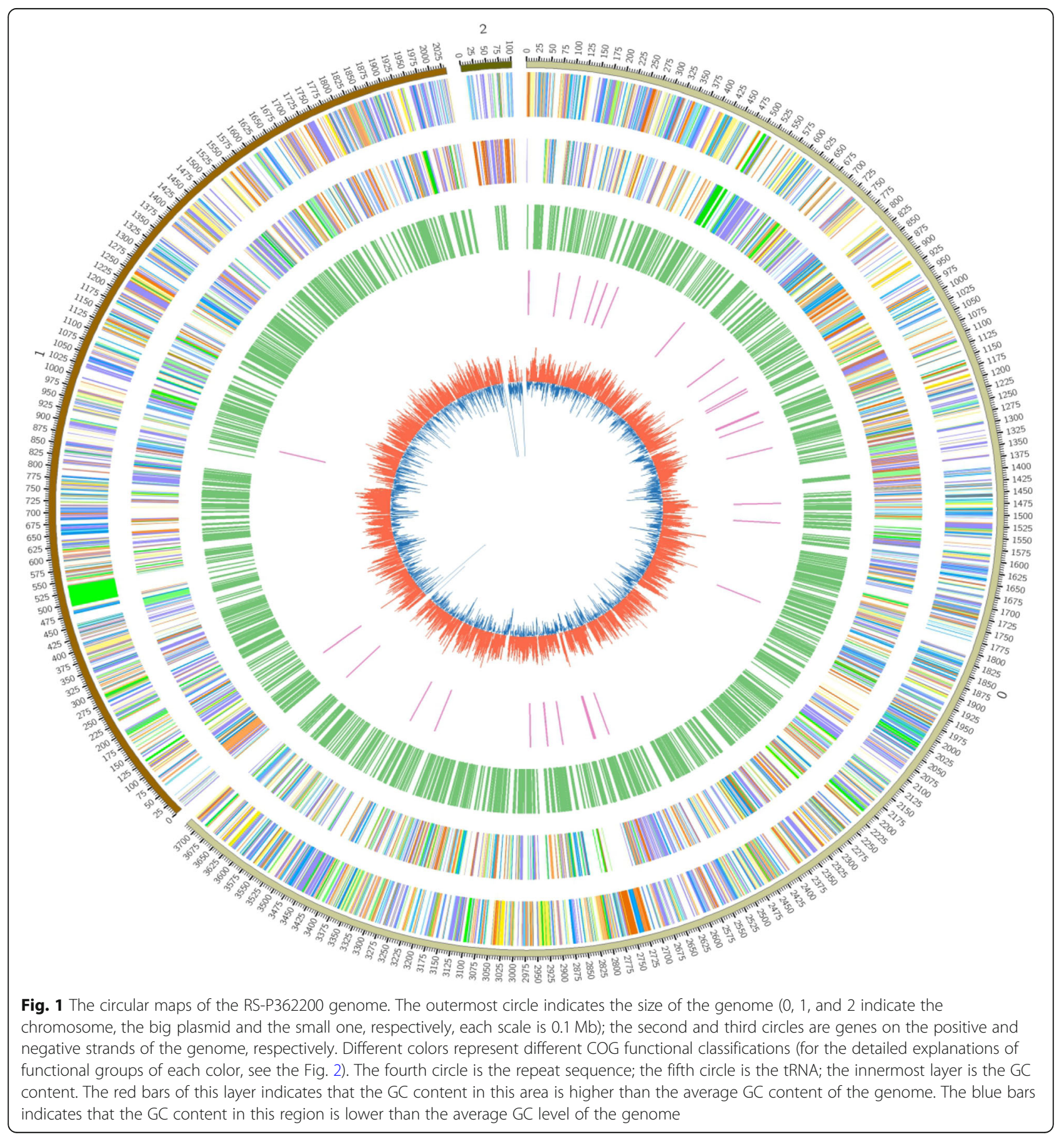


Table 2 Genomic characteristics of the Ralstonia solanacearum Rs-P.362200 strain

\begin{tabular}{lllll}
\hline Type & Chromosome & Megaplasmid & Small plasmid & Total \\
\hline Coding gene & 3342 & 1608 & 106 & 5056 \\
miRNA & 3 & 2 & 0 & 5 \\
rRNA & 306 & 102 & 0 & 408 \\
tRNA & 34 & 2 & 0 & 36 \\
Pseudogene & 3 & 6 & 3 & 12 \\
\hline
\end{tabular}

The average $\mathrm{G}+\mathrm{C}$ content of the genome was $67 \%$. The general characteristics of the Rs-P.362200 genome are listed in Table 2. Overall, 5056 coding genes were predicted in this genome with 3342, 1608 and 106 genes located in the chromosome, the megaplasmid and the small plasmid, respectively. Different strategies were used to predict noncoding RNA. The Rs-P.362200 genome contained 408 rRNAs, 36 tRNAs and 5 microRNAs. In this strain, 12 pseudogenes were identified. By using the predicted genome information and drawing a circular genome map, we can more clearly explore the distributions of genes between genome components (Fig. 1).

The predicted gene sequences were functionally annotated by using BLAST and COG, GO, and NR databases. COG and GO functional classification analyses were performed (Fig. 2). The NR species distribution statistics revealed that $95.17 \%$ of the genes belonged to the $R$. solanacearum family, which demonstrated that the strains that we sequenced were of very high quality (Fig. 3).

\section{Identification and comparative analysis of the virulence factor of Rs-P.362200}

Type III effectors (T3Es) are key to the pathogenicity of $R$. solanacearum. Searched on the T3Es protein database [25], 75 effectors were found in the Rs-P.362200 genome and different strains contain varied number of effectors. Compared with 6 reported virulent strains quite diversity presented in the effectors similarity and/or coverage and 20 effectors showed less diversity between Rs-P.362200 and HA4-1 genomes (Table 3). RipAC, RipE2, RipJ, and RipT exhibited two copies in Rs-P.362200 genome (Table 3). However, RipP1 presented three copies in the genome, which were located on the chromosome, the large plasmid and the small plasmid. The effectors that were absent in the reference genome were RipAH, RipE2 (geneID: 3_27), and RipP1 (geneID: 2_657, 3_83) (Table 3). The three effectors that were present in RsP.362200 and absent in the reference genomes were subjected to BLAST searches in the NCBI database, and it was found that other genomes contain homologous genes. It is worth noting that according to T3Es and
NCBI databases, RipP1 (geneID: 2_657, 3_83) exists only in RSCM and HA4-1 genomes (Supplementary 2).

Type three secretion system can inject effector proteins into plants, making them susceptible to diseases. We compared the structural gene clusters of type three secretion system between Rs-P.362200 and HA4-1 (Supplementary 3). Except PopC and hrcC, their genes are almost completely similar. At the same time, other virulence factors were compared, and excepting PehR, there was no other difference in virulence factors between the two strains (Supplementary 3).

\section{Phylogenetic analysis}

We downloaded the entire genome sequences of $40 R$. solanacearum strains that have been sequenced from NCBI. Among these strains, GMI1000 and YC45 belong to phylotype I, the Po82 strain belongs to phylotype II, the CMR15 strain belongs to phylotype III, and the PSI07 strain belongs to phylotype IV. The rest of the strains were isolated from different regions and hosts in China and belong to phylotype I, and the strain information used to construct the phylogenetic tree is shown in Supplementary 4. Phylogenetic trees were drawn based on the similarity of endoglucanase gene sequence from the above strains and Rs-P.362200 (Fig. 4). Phylogenic analysis places SEPPX05 and GMI1000, belonging phylotype I, as outgroup strains which diversed far from the other strains. Po82, PSI07 and CMR15 representing of respective phylotypes of II, IV and III, were also placed far from the other phylotype I strain, isolated from Asia China and India (Supplementary 4). Aparently, phylotype I diversified greatly as depending to the origins and infected plants.

\section{Comparative genomic analyses}

Collinear genes comparisons of Rs-P.362200 with six other reference $R$. solanacearum genomes were performed, which indicated that inversions and translocations are main events for genomes diversity among RSSC (Supplementary 5), with only one translocation between chromosomes of Rs-P.362200 and AH4-1 and two inversons in the megaplasmid. The percentage of collinear genes between Rs-P.362200 and HA4-1 was highest, which incoincided with the evolutionary relationships between the previous strains (Po82, CMR15, PSI07) (Fig. 4, Table 4).

Genomic comparison of the Rs-P.362200 strain with the 4 other types of strains were carried out using the genomic protein sequences, and the unique gene families of this strain were identified. Gene family analysis showed that there were 4812 genes clusters in the genome of the Rs-P.362200 strain, which could be classified into 4361 gene families, among which 29 gene families (including 113 genes) were unique to Rs-P.362200 

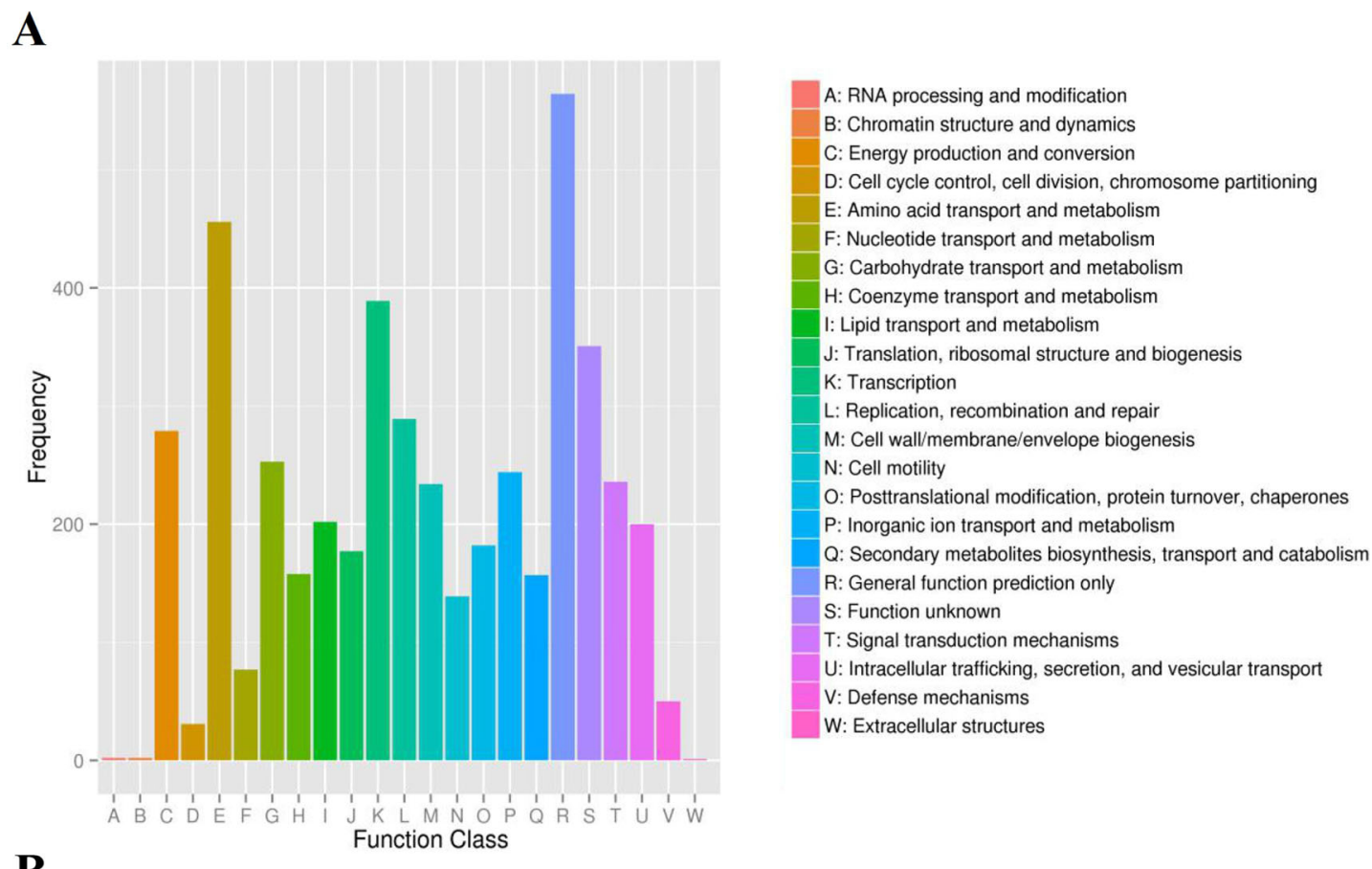

B

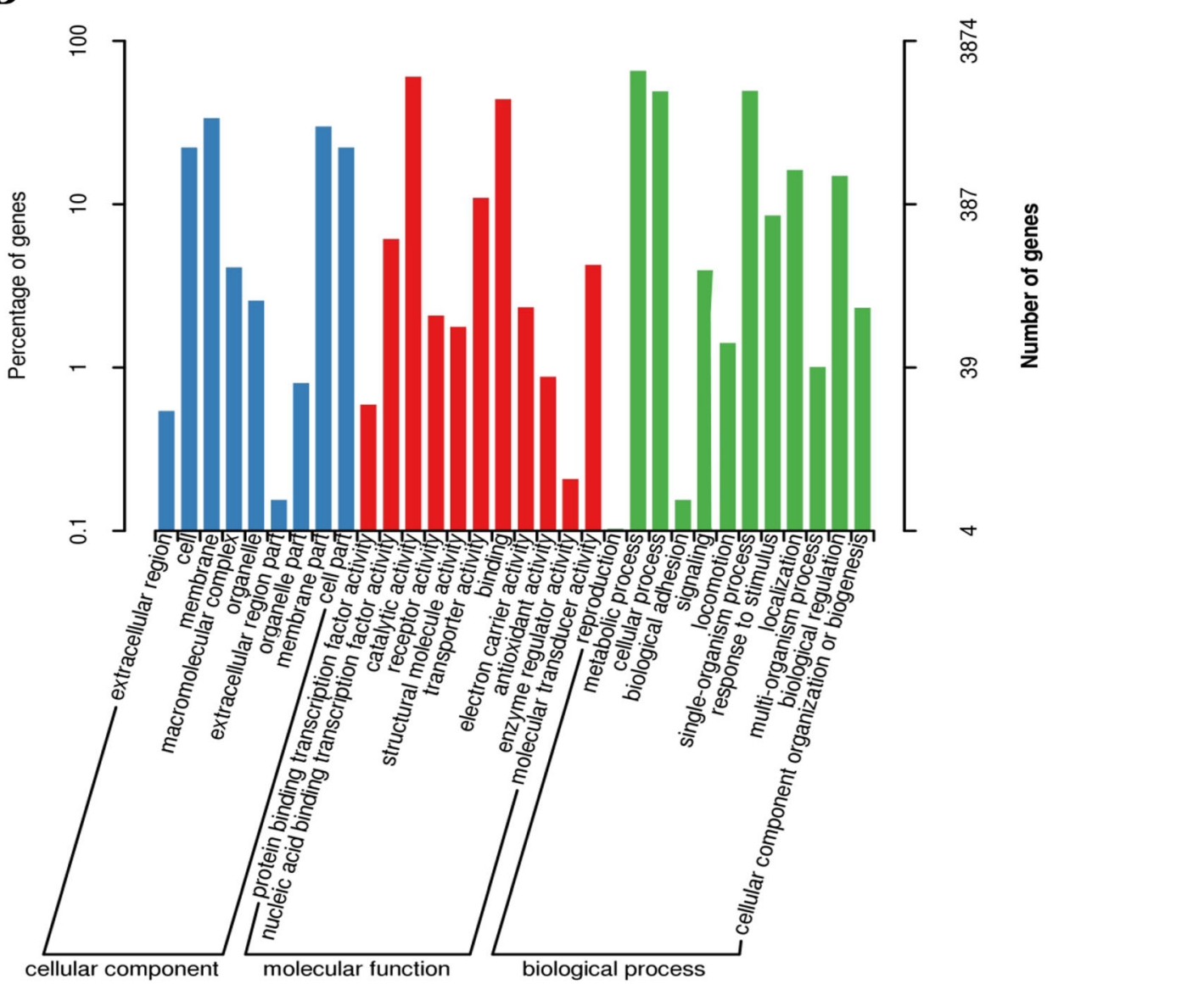

Fig. 2 Functional classification analysis in Rs-P.362200 genome. a COG classification statistics: Letters along the abscissa is the content of functional classification of COG, and the ordinate is the number of genes. $\mathbf{b}$ GO classification statistics: The abscissa is the name of each GO classification, the left of the ordinate is the percentage of the number of genes, and the right is the number of genes 


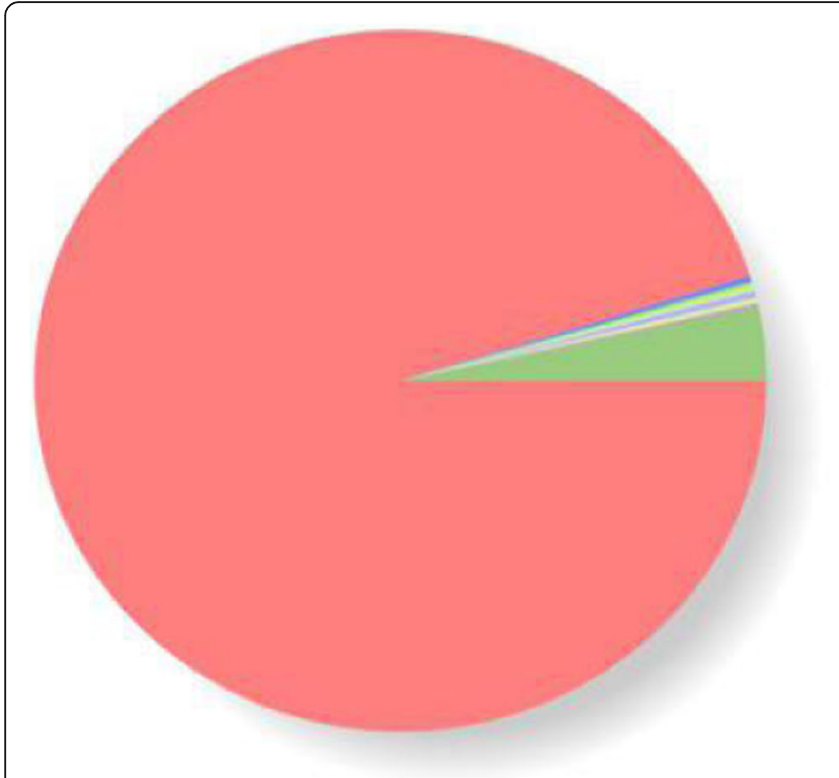

Ralstonia solanacearum [4768 95.17\%]

Ralstonia syzygii R24 [14 0.28\%]

Ralstonia pickettii [10 0.20\%]

Bacteria [9 0.18\%]

Burkholderia pseudomallei [8 0.16\%]

Ralstonia [8 0.16\%]

Ralstonia solanacearum GMI1000 [7 0.14\%]

Dickeya [6 0.12\%]

Cupriavidus metallidurans [6 0.12\%]

Ralstonia sp. AU12-08 [5 0.10\%]

Other [169 3.37\%]

Fig. 3 NR species distribution statistics. This map reflects the distribution of different homologous species genome annotated by NR. Different colors represent different homologous species

(Fig. 5, Table 5, Supplementary 6). Most of the 113 genes unique to this strain encode hypothetical proteins, transposases, putative membrane proteins and phage integrases. Enrichment of 113 unique genes indicates that RsP.362200 unique genes are involved in biological processes and molecular functions in GO (Supplementary 7). Two homologous genes (gene ID: 2_657 and 3_83) encode an avirulence protein (RipP1). These genes and effector proteins may associated with the host range of the RsP.362200 strain. Of the genomes that have been sequenced so far, only HA4-1 is isolated from peanuts and makes potatoes susceptible to disease. At present, the pathogenicity of Rs-P.362200 strain to other plants has not been reported. However, we have used the RsP.362200 isolated from peanut to inoculate tobacco without any infection. We compared the genomic information of HA4-1 and Rs-P.362200, and the number of genomic islands and Prophages of Rs-P.362200 genome was less than that of HA4-1(Supplementary 8-1). Comparing HA4-1 and Rs-P.362200 genomes, there are 147 gene families unique to HA4-1 genome and 151 gene families unique to Rs-P.362200. Enriching the unique gene family showed that the unique gene of HA4-1 participated in the biological process and molecular function in GO, while the unique gene of Rs-P.362200 participated in the biological process in GO (Supplementary 9).

\section{Horizontal gene transfer is extensively observed in the Rs-P.362200 genome}

Many studies have shown that horizontal gene transfer (HGT) is the main driving force for the evolution of prokaryotes, affecting all aspects of prokaryotes [26, 27]. Pathogenicity islands (PAIs) are related to the pathogenesis of bacteria, and some pathogenic genomic islands can cause horizontal gene transfer in closely related species. Through PAI analysis, it was found that 378 genes in the RsP.362200 strain were distributed in 30 PAIs (Supplementary 8-2). Most genes in the PAIs were hypothetical proteinencoding genes, and some were type III effector protein genes, such as RipAX2, RipB, RipT, RipP1 (geneID: 1 1183), RipAH, RS-T3E-Hyp6 and RipE2 (geneID: 1_1224).

Horizontal gene transfer in prokaryotes is mainly achieved through three mechanisms: transformation, conjugation, and transduction [28]. Transduction is carried out by bacteriophages, which can be integrated into bacterial chromosomes in the form of prophages and remain latent for a long time. In this study, 363 genes in 6 prophages were identified (Supplementary 8-3). RipE2 (geneID: 3_27), RipAK, RipP2, RipT, RipP1 (geneID: 1 1183), RipAH, RS-T3E-Hyp6 and RipE2 (geneID: $1_{-}$ 1224) were distributed in prophage sequences. Interestingly, RipP1 (geneID: 1_1183), RipAH, RS-T3E-Hyp6 and RipE2 (geneID: 1_1224) were located in genomic islands, and prophages. These genes, co-existing in genomic islands and prophages, are found in strains from different sources (Supplementary 2). May be this pathogenic genes obtained from other bacteria through horizontal gene transfer.

\section{Discussion}

RSSC is one of the ten most harmful plant pathogens in the world and can cause the withering of many 
Table 3 Comparison analysis of type III effector proteins genes (Coverage\%/ldentity\%) in Rs-P.362200 and other strains

\begin{tabular}{|c|c|c|c|c|c|c|c|}
\hline Effector name & Rs-P.362200 gene ID & GMI1000 & YC45 & CMR15 & PSI07 & Po82 & HA4-1 \\
\hline RipA1 & 1_3262 & 95/99 & $100 / 98$ & absent & absent & absent & $100 / 100$ \\
\hline RipA2 & 2_1476 & $100 / 100$ & $100 / 100$ & $100 / 93$ & $100 / 79$ & $97 / 78$ & $100 / 100$ \\
\hline RipA3 & 2_596 & $96 / 98$ & $90 / 54$ & $100 / 90$ & $96 / 82$ & $100 / 69$ & $96 / 99$ \\
\hline RipA4 & 2_597 & $100 / 99$ & $96 / 99$ & $100 / 89$ & $100 / 80$ & $90 / 53$ & $100 / 100$ \\
\hline RipA5 & 2_793 & 99/97 & 99/97 & absent & $100 / 79$ & $97 / 55$ & $99 / 99$ \\
\hline RipAB & 2_627 & $100 / 99$ & $100 / 99$ & 99/93 & $100 / 77$ & $100 / 70$ & $100 / 100$ \\
\hline \multirow[t]{2}{*}{ RipAC } & $2 \_625$ & $97 / 100$ & absent & $97 / 46$ & $99 / 69$ & $93 / 52$ & absent \\
\hline & $2 \_626$ & 99/99 & absent & $99 / 52$ & $99 / 80$ & $99 / 66$ & absent \\
\hline RipAD & 2_1349 & $100 / 98$ & $100 / 99$ & $100 / 80$ & $100 / 74$ & $98 / 69$ & $100 / 100$ \\
\hline RipAE & 2_617 & $100 / 99$ & $100 / 100$ & $100 / 97$ & $100 / 96$ & $100 / 97$ & $100 / 100$ \\
\hline RipAF1 & 2_571 & $100 / 98$ & absent & $100 / 87$ & absent & $100 / 58$ & $100 / 100$ \\
\hline RipAH & 1_1184 & absent & absent & absent & absent & absent & absent \\
\hline RipAJ & 1_3299 & $100 / 99$ & $100 / 100$ & $100 / 73$ & $100 / 69$ & $100 / 71$ & $100 / 100$ \\
\hline RipAK & 1_3050 & $100 / 100$ & $100 / 99$ & absent & absent & absent & $100 / 100$ \\
\hline RipAL & $2 \_480$ & absent & absent & $99 / 83$ & $100 / 99$ & $96 / 81$ & $100 / 100$ \\
\hline RipAM & 1_2241 & $100 / 100$ & $100 / 100$ & $100 / 94$ & $100 / 83$ & $89 / 74$ & $100 / 100$ \\
\hline RipAN & 2_595 & 97/99 & $100 / 99$ & $97 / 85$ & $92 / 74$ & $97 / 70$ & $96 / 99$ \\
\hline RipAO & $2 \_630$ & $100 / 97$ & $100 / 98$ & $100 / 83$ & $100 / 54$ & absent & $100 / 100$ \\
\hline RipAP & 2_982 & absent & $100 / 99$ & $100 / 84$ & absent & $100 / 79$ & $100 / 100$ \\
\hline RipAQ & $2 \_621$ & $100 / 99$ & $100 / 100$ & $100 / 98$ & $100 / 93$ & $100 / 92$ & $100 / 100$ \\
\hline RipAR & 2_1003 & $100 / 98$ & $100 / 99$ & $100 / 83$ & $95 / 72$ & $99 / 65$ & $95 / 57$ \\
\hline RipAS & 2_1121 & $89 / 99$ & $100 / 99$ & $100 / 89$ & absent & $97 / 52$ & $100 / 100$ \\
\hline RipAT & 2_1125 & $74 / 98$ & $100 / 99$ & $99 / 64$ & $74 / 71$ & $99 / 63$ & $74 / 99$ \\
\hline RipAU & 2_1202 & $100 / 97$ & $100 / 98$ & $100 / 82$ & $99 / 70$ & $99 / 70$ & $100 / 100$ \\
\hline RipAV & $2 \_488$ & $100 / 98$ & $100 / 98$ & $100 / 88$ & absent & $100 / 87$ & $100 / 100$ \\
\hline RipAW & 2_1218 & $82 / 97$ & $82 / 98$ & $82 / 85$ & $100 / 66$ & $100 / 63$ & $82 / 99$ \\
\hline $\operatorname{RipAX2}$ & 2_329 & $89 / 100$ & absent & absent & absent & absent & $88 / 100$ \\
\hline RipAY & 2_791 & $83 / 95$ & $100 / 99$ & $100 / 83$ & $95 / 67$ & $100 / 60$ & $82 / 99$ \\
\hline RipB & 1_1817 & $100 / 100$ & $100 / 99$ & $98 / 80$ & $100 / 79$ & $100 / 72$ & $100 / 100$ \\
\hline RipBC & 1_2236 & $100 / 100$ & $100 / 100$ & $100 / 99$ & $100 / 98$ & $100 / 93$ & $100 / 100$ \\
\hline RipBF & 2_1512 & $100 / 99$ & absent & $100 / 96$ & absent & $100 / 96$ & $100 / 100$ \\
\hline RipBM & 2_1577 & absent & absent & $100 / 90$ & $100 / 94$ & absent & $100 / 100$ \\
\hline RipC1 & 2_1006 & $100 / 98$ & $100 / 98$ & absent & $95 / 96$ & $96 / 70$ & $100 / 100$ \\
\hline RipC2 & 2_94 & $84 / 91$ & $100 / 98$ & $100 / 67$ & $100 / 83$ & $100 / 63$ & $100 / 100$ \\
\hline RipE1 & 1_2140 & $100 / 99$ & absent & $100 / 87$ & $100 / 79$ & $100 / 85$ & $100 / 100$ \\
\hline \multirow[t]{2}{*}{ RipE2 } & 1_1224 & absent & absent & absent & 78/97 & $100 / 89$ & $100 / 100$ \\
\hline & 3_27 & absent & absent & absent & absent & absent & absent \\
\hline RipF1 & 2_640 & $85 / 96$ & $86 / 95$ & $85 / 94$ & $86 / 85$ & $85 / 87$ & $85 / 94$ \\
\hline RipG1 & 2_649 & $100 / 99$ & $100 / 99$ & absent & $92 / 53$ & absent & $100 / 100$ \\
\hline RipG2 & $2 \_430$ & $100 / 98$ & $100 / 96$ & $100 / 81$ & $100 / 64$ & $100 / 73$ & $94 / 99$ \\
\hline RipG3 & 2_1452 & $100 / 98$ & $100 / 98$ & $100 / 86$ & $100 / 71$ & $100 / 59$ & $100 / 100$ \\
\hline RipG4 & 1_418 & $87 / 99$ & $100 / 99$ & $100 / 78$ & $100 / 51$ & $100 / 58$ & $86 / 99$ \\
\hline RipG5 & $1-419$ & $81 / 99$ & $81 / 99$ & $80 / 89$ & $81 / 74$ & $81 / 65$ & $100 / 100$ \\
\hline RipG7 & 1_645 & $98 / 69$ & $98 / 69$ & $98 / 68$ & $99 / 73$ & $99 / 65$ & $100 / 100$ \\
\hline
\end{tabular}


Table 3 Comparison analysis of type III effector proteins genes (Coverage\%/ldentity\%) in Rs-P.362200 and other strains (Continued)

\begin{tabular}{|c|c|c|c|c|c|c|c|}
\hline Effector name & Rs-P.362200 gene ID & GMI1000 & YC45 & CMR15 & PSI07 & Po82 & HA4-1 \\
\hline RipH1 & 1_571 & $100 / 97$ & $100 / 97$ & $100 / 82$ & $98 / 65$ & $98 / 39$ & $100 / 99$ \\
\hline $\mathrm{RipH} 2$ & 2_1579 & $92 / 97$ & $100 / 97$ & $100 / 82$ & $98 / 55$ & $98 / 49$ & $100 / 100$ \\
\hline RipH3 & 2_1525 & $100 / 99$ & $100 / 99$ & $100 / 86$ & $98 / 71$ & $99 / 79$ & $100 / 100$ \\
\hline Ripl & 1_2027 & $100 / 100$ & $100 / 100$ & $100 / 87$ & $100 / 93$ & $100 / 82$ & $100 / 100$ \\
\hline \multirow[t]{2}{*}{ RipJ } & 2_653 & $98 / 71$ & absent & $94 / 26$ & absent & $100 / 72$ & $100 / 100$ \\
\hline & 2_679 & $97 / 67$ & absent & absent & absent & $97 / 72$ & $97 / 71$ \\
\hline RipL & 2_1560 & $100 / 99$ & $100 / 97$ & $99 / 81$ & absent & $100 / 61$ & $100 / 100$ \\
\hline RipM & 1_483 & $100 / 99$ & $100 / 98$ & $100 / 89$ & $99 / 80$ & absent & $100 / 100$ \\
\hline RipN & 2_905 & $100 / 98$ & $100 / 99$ & $100 / 89$ & $98 / 73$ & $100 / 73$ & $100 / 100$ \\
\hline RipO1 & $2 \_116$ & $100 / 99$ & absent & $100 / 91$ & absent & $96 / 86$ & $100 / 100$ \\
\hline \multirow[t]{3}{*}{ RipP1 } & 1_1183 & $100 / 95$ & absent & absent & absent & $100 / 95$ & $100 / 100$ \\
\hline & 2_657 & absent & absent & absent & absent & absent & $100 / 100$ \\
\hline & 3_83 & absent & absent & absent & absent & absent & $100 / 100$ \\
\hline RipP2 & 1_3098 & $100 / 100$ & $100 / 100$ & $100 / 96$ & absent & $100 / 84$ & $100 / 100$ \\
\hline RipQ & 2_1046 & 70/99 & 70/99 & 70/76 & absent & $100 / 71$ & $69 / 99$ \\
\hline RipR & 2_1050 & $100 / 100$ & $100 / 100$ & $100 / 91$ & $100 / 82$ & $100 / 80$ & $100 / 100$ \\
\hline RipS1 & 1_2108 & $100 / 99$ & $100 / 99$ & $100 / 91$ & $100 / 75$ & $100 / 89$ & $99 / 70$ \\
\hline RipS2 & 2_1105 & 98/99 & $91 / 50$ & $98 / 91$ & $99 / 78$ & $98 / 75$ & $100 / 99$ \\
\hline RipS3 & 2_699 & $100 / 98$ & $100 / 98$ & $100 / 92$ & $100 / 77$ & $100 / 76$ & $100 / 100$ \\
\hline RipS4 & 1_454 & 98/98 & 99/99 & $99 / 83$ & $91 / 62$ & $97 / 72$ & $92 / 63$ \\
\hline RipS5 & 2_90 & $100 / 99$ & $100 / 99$ & $100 / 85$ & $100 / 76$ & $100 / 70$ & $100 / 100$ \\
\hline RipS6 & 1_3270 & $89 / 99$ & $89 / 99$ & $94 / 49$ & $93 / 48$ & $91 / 49$ & $89 / 99$ \\
\hline RipS7 & 1_3142 & $100 / 99$ & $100 / 100$ & 100/97 & $100 / 92$ & $100 / 92$ & $100 / 100$ \\
\hline RipS8 & 1_457 & $79 / 63$ & $100 / 98$ & $78 / 61$ & $100 / 90$ & $78 / 63$ & $100 / 100$ \\
\hline \multirow[t]{2}{*}{ RipT } & 1_1155 & $71 / 100$ & absent & absent & $99 / 89$ & absent & $100 / 100$ \\
\hline & 1_1221 & $71 / 87$ & absent & absent & $100 / 94$ & absent & $99 / 90$ \\
\hline RipTAL & 1_432 & $100 / 99$ & $100 / 99$ & absent & $64 / 75$ & absent & $100 / 100$ \\
\hline RipTPS & $2 \_487$ & $100 / 99$ & $100 / 99$ & $100 / 96$ & $94 / 76$ & $80 / 44$ & $100 / 100$ \\
\hline RipU & 2_979 & absent & $100 / 99$ & absent & $100 / 77$ & $100 / 78$ & $100 / 100$ \\
\hline RipV1 & 1_653 & $61 / 97$ & $61 / 97$ & $58 / 85$ & $54 / 71$ & $53 / 63$ & $100 / 100$ \\
\hline RipW & 1_2687 & $100 / 99$ & $100 / 99$ & $100 / 90$ & $100 / 84$ & $100 / 78$ & $100 / 100$ \\
\hline RipX & $2 \_628$ & $100 / 95$ & $100 / 95$ & $100 / 77$ & $100 / 74$ & $99 / 63$ & $100 / 100$ \\
\hline RipY & 1_1806 & $99 / 62$ & $99 / 62$ & $99 / 61$ & $99 / 61$ & $99 / 60$ & $100 / 100$ \\
\hline RipZ & $2 \_612$ & $100 / 99$ & $100 / 99$ & $100 / 96$ & $100 / 88$ & $100 / 86$ & $100 / 100$ \\
\hline RS-T3E-Hyp12 & 2_1563 & 100/99 & $100 / 100$ & $100 / 94$ & $100 / 90$ & $100 / 81$ & $100 / 100$ \\
\hline RS-T3E-Hyp6 & 1_1198 & absent & absent & $71 / 90$ & absent & absent & $72 / 99$ \\
\hline RS-T3E-Hyp8 & $2 \_216$ & $100 / 100$ & $100 / 99$ & $100 / 99$ & $100 / 97$ & $100 / 94$ & $100 / 100$ \\
\hline Total & 75 & 71 & 61 & 65 & 61 & 66 & 77 \\
\hline
\end{tabular}

important crops. Understanding of the whole-genome characteristics of RSSC is helpful for studying the pathogenic mechanism of $R$. solanacearum at the gene level to provide a theoretical basis or strategies for the effective control of bacterial wilt. Since the whole-genome sequencing of the first $R$. solanacearum strain, GMI1000, in 2002 [12], molecular biology and microbial whole-genome sequencing techniques have been considerably improved, and an increasing number of strains have been sequenced. Although $R$. solanacearum was 


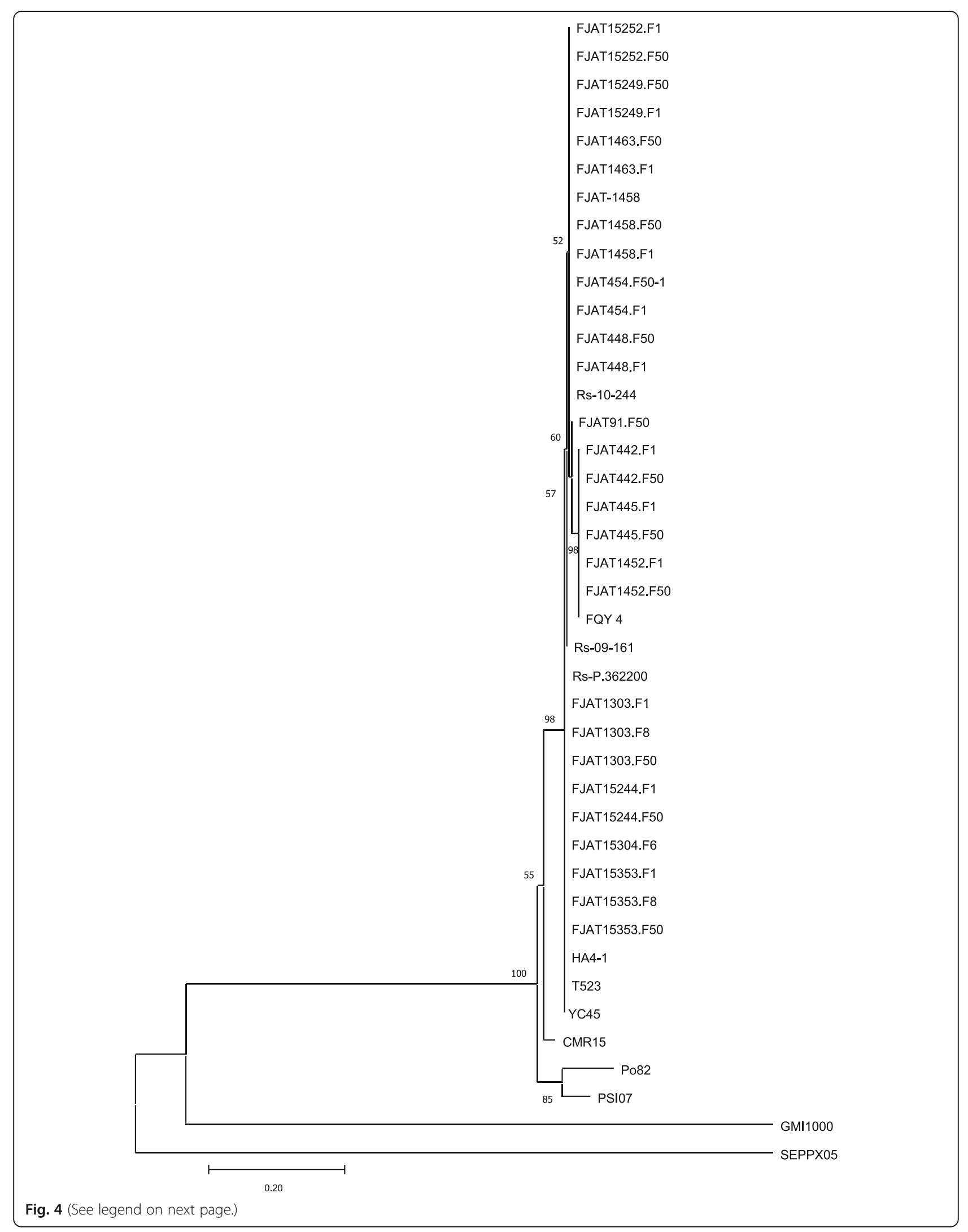


(See figure on previous page.)

Fig. 4 Genetic relationship between Rs-P.362200 and other virulent strains. The evolutionary relationship was inferred using the Neighbor-Joining method. Phylogenetic tree based on the comparison of endoglucanase gene sequence from $R$. solanacearum strains. The percentage of replicate trees in which the associated taxa clustered together in the bootstrap test (1000 replicates) are shown next to the branches. The bottom 0.2 scale represents two nucleotide change per 100-nucleotide position

found on peanuts in 1930s, it was not until 2019 that Tan first released the strains isolated from peanuts [17]. Conquering peanut bacterial wilt is a worldwide problem, but there are few studies on the pathogenic mechanism of peanut bacterial wilt. According to the current research, HA4-1 can make peanut and potato susceptible. However, whether Rs-P.362200 will make other plants such as potato susceptible to disease remains to be explored further, yet it cannot infect tobacco plants. The comparative genomic analysis of Rs-P.362200 and other reference genomes revealed the diversity of Type III effector proteins and host-specific candidate genes. The comparison of genomic information between HA41 and Rs-P.362200 shows that the number of genomic islands and prophages in HA4-1 genome is more than that in Rs-P.362200. Maybe it has something to do with the host range of the strain, and more strains isolated from peanuts need to be sequenced to better explain this problem.

Many Type III effector proteins have been identified as virulence factors or avirulent proteins in $R$. solanacearum. Macho and other authors have shown that RipD, RipP2, RipAC, RipY, RipA1, RipA2 and RipD can improve the adaptability of $R$. solanacearum in the host. RipW, RipAR and eight proteins of the RipG family can form E3 ubiquitin ligases in the host, which ubiquitinate host defense-related proteins, thereby disrupting the host defense response [29, 30]. Yuying et al. showed that RipAY synthesized g-glutamylcyclotransferase in the host to reduce the activity of glutathione to inhibit the plant immune response [31]. Some effectors play the role of avirulence proteins, which can induce an immune response in the host plant and make the host resistant to disease, as observed for RipAA, RipP1, RipAX1, and RipB [25, 32-34]. In our study, according to the effector protein database and gene functional annotation, 75 type III effector proteins were identified in the Rs-P.362200

Table 4 Comparison of collinearity between Rs-P.362200 and other strains of Ralstonia solanacearum

\begin{tabular}{ll}
\hline Strain name & Collinear with Rs-P.362200 (\%) \\
\hline HA4-1 & 88.75 \\
GMI1000 & 80.68 \\
CMR15 & 74.89 \\
YC45 & 72.74 \\
P082 & 70.4 \\
PSI07 & 69.66 \\
\hline
\end{tabular}

genome. Two homologous genes of RipP1 (geneID: 2 657 and 3_83) only exist in RSCM and HA4-1 genomes. The geographical location of strain HA4-1 and RSCM is in Asia, the host of HA4-1 is peanut and the host of RSCM is Cucurbita maxima. It is possible that these two genes are the key virulence factors in the pathogenic process of some special hosts. At present, the homologous gene of RipE2 (3_27) is only found in three strains (UA-1612, UA-1611 and IBSBF1503) isolated from South America. The diversity of $R$. solanacearum T3Es may determine the host range and pathogenicity of $R$. solanacearum.

Based on the comparative genomic analysis of RsP.362200 and 5 other reference genomes for $R$. solanacearum, it was found that there were 113 genes unique to the Rs-P.362200 genome. Two of these specific genes belong to the RipP1 (geneID: 2_657 and 3_83) gene family of pathogenic factors of the $R$. solanacearum, which may be related to host specificity. Their function can only be identified by constructing gene mutants and performing corresponding phenotypic analysis in the later stage. Although the hosts of HA4-1 and Rs-P.362200 strains are the same, they have specific genes belonging to their own genomes (Supplementary 9). The genetic diversity of $R$. solanacearum strains may be the reason for the wide host range and difficulty in control of bacterial wilt at present.

Horizontal gene transfer can enhance the adaptability of bacteria to the environments, and genome islands and prophages are the most important mobile elements in HGT [35]. The coding regions of genome islands usually contains large numbers of virulence gene clusters which encode the virulence factors of many pathogenic bacteria [26]. The nucleic acids of mild bacteriophages, i.e. prophage sequences may allow some bacteria to acquire antibiotic resistance, enhance bacterial adaptability to the environments, improve bacterial adhesion or cause the bacteria to become pathogenic [36]. The analysis showed that the strain contained 30 genomic islands and 6 prophages. Interestingly, RipT, RipP1, RipAH, and RipE2 were found in both genomic islands and prophages. These effector factors may be obtained from other bacterial genomes and transferred to other bacterial genomes via horizontal gene transfer. The strains containing these genes may play an important role in the pathogenicity and adaptation of $R$. solanacearum in the environment. Although these phenomena contribute to explaining the wide host range and high pathogenicity 


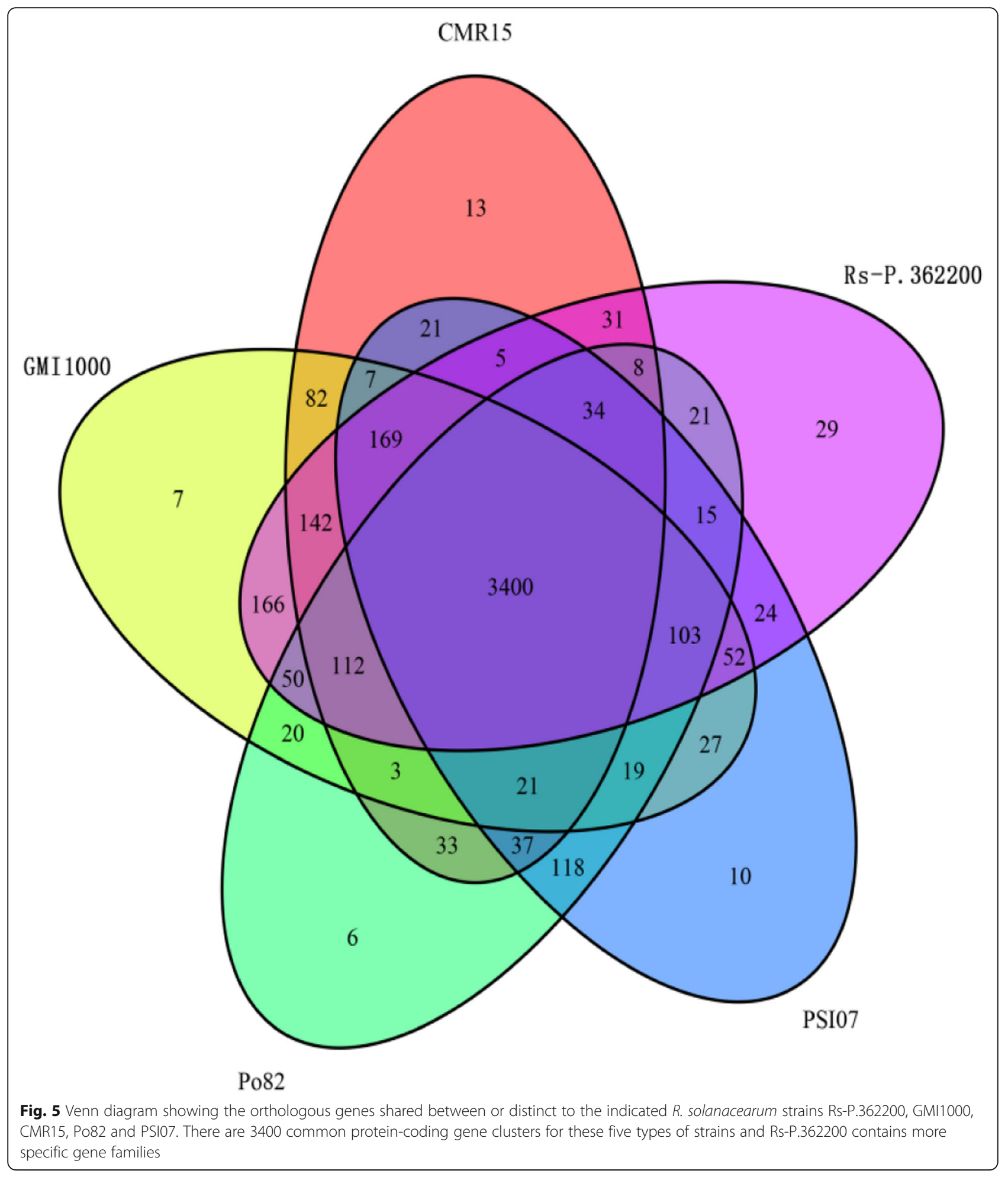

of $R$. solanacearum, subsequent experiments are needed to verify their occurrence.

The evolutionary relationships among $R$. solanacearum strains are closely related to their geographical origin [10]. Kangetal clarified the genetic diversity of $R$. solanacearum in the Yangtze River Valley and southern China, and $95 R$. solanacearum strains from 9 main peanut-producing areas have been identified as belonging to phylotype I (Asian branch type) [37]. Phylogenetic analysis of 41 strains from 4 phylotypes mainly type I 
Table $\mathbf{5}$ Gene family classification statistics

\begin{tabular}{lllll}
\hline $\begin{array}{l}\text { Species } \\
\text { name }\end{array}$ & $\begin{array}{l}\text { Total } \\
\text { gene } \\
\text { number }\end{array}$ & $\begin{array}{l}\text { Gene } \\
\text { cluster } \\
\text { number }\end{array}$ & $\begin{array}{l}\text { Total } \\
\text { family } \\
\text { number }\end{array}$ & $\begin{array}{l}\text { Unique gene } \\
\text { family number }\end{array}$ \\
\hline CMR15 & 4749 & 4361 & 4118 & 13 \\
GM11000 & 4833 & 4663 & 4380 & 7 \\
PS107 & 4664 & 4397 & 4062 & 10 \\
P082 & 4526 & 4279 & 4000 & 6 \\
Rs-P.362200 & 5056 & 4812 & 4361 & 29 \\
\hline
\end{tabular}

strains demonstrated that type I strains from tomatos they can be classified into different groups because of geographical origins, and the diverse types and hosting plants also make the diversity (Fig. 4). The genetic relationship between Rs-P.362200 and other pathogenic strains of tomatoes is similar (Fig. 4; Supplementary 4). It can be inferred that the genetic relationship between strains has little to do with whether the host is the same or not. The results again confirmed that the high diversity of the $R$. solanacearum species complex makes the species with the widest range of hosts.

\section{Conclusions}

In this study, novel complete genome of the peanut bacterial wilt pathogen was sequenced with distinct diversity. Comparative genomic analysis of different phylotypes of strains provides the evidence for the genetic diversity and host specificity. The reason of wide host range and strong adaptability of $R$. solanacearum was further validated from the events of horizontal gene transfer and the diverse strains with the same host of peanut. The evolutionary relationship between $R$. solanacearum strains was indicated to be more related to geographic origins than the host variance. In short, the results provide an important basis for understanding the pathogenic mechanism of peanut bacterial wilt and lays a theoretical foundation for future research on the interaction between $R$. solanacearum and peanut.

\section{Materials and methods}

\section{Preparation of strains}

The RS-p.362200 strain was donated by the Fujian Academy of Agricultural Sciences (isolated from pathogenic plants in main peanut production area at Fuqin city, Fujian Province in China in 2014). Single colonies were selected after 2 days of culture in TTC medium $(1 \mathrm{~g}$ hydrolyzed casein, $5 \mathrm{~g}$ glucose, $10 \mathrm{~g}$ peptone, $0.5 \mathrm{~g}$ 2,3,5triphenyltetrazolium chloride, $15 \mathrm{~g}$ agar, dissolved in $1 \mathrm{~L}$ water, $\mathrm{pH}$ 7.4.) at $28^{\circ} \mathrm{C}$. The selected clones were grown in SPA liquid medium $\left(0.5 \mathrm{~g} \mathrm{KH}_{2} \mathrm{PO}_{4}, 20 \mathrm{~g}\right.$ sucrose, 0.25 $\mathrm{g} \mathrm{MgSO}_{4}, 5 \mathrm{~g}$ peptone, dissolved in $1 \mathrm{~L}$ water, $\mathrm{pH}$ 7.4.) for $12 \mathrm{~h}$ at $28^{\circ} \mathrm{C}$, followed by centrifugation at $4000 \mathrm{rpm}$ for $10 \mathrm{~min}$ to collect cells. The prepared strains were used for subsequent experiments.

\section{Genome sequencing and assembly}

Genomic DNA was extracted with the TIANamp Bacteria DNA Kit (TIANGEN Beijing). A 20 kb library was constructed from the bacterial genome and sequenced via the single-molecule real-time (SMRT) sequencing method [38, 39] developed by Pacific Biosciences to obtain sequencing data. The assembly software MHAP [23, $24]$ was used to assemble the filtered subread data.

\section{Genome structure analysis}

RepeatMasker software [40] was used to mask the repetitive sequence of the bacterial genome. The coding genes of the assembled genome were predicted with the software prodigal [41]. The predicted protein sequences were used to identify homologous gene sequences in the NCBI database by using BLASTP [42], after which immature stop codons and frameshift mutations in the gene sequences were then identified by GeneWise [43], and pseudogenes were annotated. IslandPath-DIOMB software [44] was used to predict the pathogenicity islands in the bacterial genome. The software PhiSpy [45] was used to predict the prophages. And the predicted genomic information, such as repeat sequences and GC content, was used to draw the circular genome map with the CIRCOS tool [46].

\section{Functional annotation of the genome}

Gene function annotations were performed based on the NR (Non-Redundant Protein Database) [47], COG (Clusters of Orthologous Groups) [48], and GO (Gene Ontology) [49] databases. Type III effector proteins were predicted by using the T3E database [25]. The clusterProfiler software [50] was used for the enrichment analysis of GO and KEGG.

\section{Identification of orthologous genes}

The protein sequences of $R$. solanacearum RS-P.362200, GMI1000, Po82, CMR15, PSI07 and HA4-1 were classified with OrthoMCL software [51] to identify the specific gene family of the strains. The identification of orthologs among the $6 R$. solanacearum strains was also performed via OrthoMCL analysis. The protein sequences of putative orthologous groups including only single-copy genes (one-to-one orthologs) that were shared by all $R$. solanacearum strains were aligned using MUSCLE software with the default parameters [52]. Single-copy genes were identified as those for which only one gene per $R$. solanacearum strain was included in the orthologous group. Comparative analysis of orthologs and the copy numbers was performed among RSp.362200 and the other strains for visualization with InteractiVenn using Custom Perl scripts. 


\section{Construction of phylogenetic tree}

The evolution relationship among 41 strains including all four phylotyps was inferred using the Neighbor-Joining method [53]. The optimal tree with the sum of branch length $=2.61573329$ is shown. The percentage of replicate trees in which the associated taxa clustered together in the bootstrap test (1000 replicates) are shown next to the branches [54]. The tree is drawn to scale, with branch lengths (next to the branches) in the same units as those of the evolutionary distances used to infer the phylogenetic tree. The evolutionary distances were computed using the Poisson correction method [55] and are in the units of the number of amino acid substitutions per site. The analysis involved amino acid sequences. All ambiguous positions were removed for each sequence pair. There were a total of 498 positions in the final dataset. Evolutionary analyses were conducted in MEGA7 [56].

\section{Comparative genomic analysis}

The Multiple Collinearity Scan Toolkit (MCScanX) was employed to search for collinear genes between RSp.362200 and the other 5 R. solanacearum strains [57]. As a sign of collinearity between genomes, the percentage of collinear genes in each paired strain (RS-p.362200 vs GMI1000, RS-p.362200 vs CMR15, RS-p.362200 vs YC45, RS-p.362200 vs Po82, RS-p.362200 vs PSI07, and RSp.362200 vs HA4-1) was also analyzed (Supplementary 2).

\section{Supplementary Information}

The online version contains supplementary material available at https://doi. org/10.1186/s12866-021-02157-7.

Additional file 1: Supplementary 1. Compare efficiency statistics. Additional file 2: Supplementary 2. The distribution of specific effector proteins in Ralstonia solanacearum species complex.

Additional file 3: Supplementary 3. Type III secretion system and other virulence factors.

Additional file 4: Supplementary 4. The strain information used to construct the phylogenetic tree.

Additional file 5: Supplementary 5. The collinear relationship between Rs-P.362200 strain and other strains.

Additional file 6: Supplementary 6. Gene analysis related to specific genes in Rs-P.362200.

Additional file 7: Supplementary 7. Go classification statistics of specific genes of Rs-P.362200 strain.

Additional file 8: Supplementary 8-1. Comparative of HA4-1 and RsP.362200 genomic features. Supplementary 8-2. Analysis of genes in genomic pathogenicity islands. Supplementary 8-3. Analysis of genes in prophages.

Additional file 9: Supplementary 9. Comparative genomic analysis of R. solanacearum strains Rs-P.362200 and HA4-1.

\section{Acknowledgements}

We thank professors Furu Chen and Bo Liu from Fujian Academy of Agriculture Sciences for the kind help on the toxic strains collections. The authors gratefully acknowledge the financial supports by the National Science Foundation of China under Grant number: U1705233, 32072103,
31701463. We sincerely appreciate the support of the Science and Technology Foundation of Fujian Province of China (2018N0004).

\section{Authors' contributions}

Kun $C$ was the experimental designer and executor of this study, and completed the analysis of the experimental data and wrote the paper manuscript. Lihui W, Hua C, Chong Z, Shanshan W, Panpan C, and Huasong $Z$ were responsible for part of the experiment and data analysis. Shaokang $L$, Huiwen F, Menghan Liu, Tao S and Qiang Y participated in the sample sampling. Weijian $\mathrm{Z}$ is the person in charge of the project, guiding the experimental design, experimental process and data analysis, and is responsible for the writing and revision of the initial paper manuscript. All the authors read and agree on the final manuscript.

\section{Funding}

This work was support by the National Science Foundation of P. R. China (U1705233, 32072103, 31701463). This project was partially supported by the Science and Technology Foundation of Fujian Province of China (2018N0004).

\section{Availability of data and materials}

The pacbio RSII rawdata of RS WGS was deposited in the NCBI SAR database under the accession number PRJNA668065, is available from [https://www. ncbi.nlm.nih.gov/bioproject/?term=PRJNA668065].

\section{Declarations}

Ethics approval and consent to participate

Not applicable.

\section{Consent for publication}

Not applicable.

\section{Competing interests}

The authors declare that they have no competing interests.

Received: 20 September 2020 Accepted: 8 March 2021

Published online: 19 April 2021

\section{References}

1. Xu J, Feng J. Advances in research of genetic diversity and pathogenome of Ralstonia solanacearum species complex. Sci Agric Sin. 2013;46(14):2902-9. https://doi.org/10.3864/j.issn.0578-1752.2013.14.006.

2. Zheng XA. A systemic screening of effectors in Ralstonia Solanacearum and virulence study of Rip25 in potato. Huazhong Agric Univ. 2018.

3. Álvarez B, López MM, Biosca EG. Survival strategies and pathogenicity of Ralstonia solanacearum phylotype II subjected to prolonged starvation in environmental water microcosms. Microbiology. 2008;154(11):3590-8. https://doi.org/10.1099/mic.0.2008/019448-0.

4. Guarischi-Sousa R, Puigvert M, Coll NS, Siri MI, Pianzzola MJ, Valls M, et al. Complete genome sequence of the potato pathogen Ralstonia solanacearum UY031. Sand Genomic Sci. 2016;11(1):7. https://doi.org/10.11 86/s40793-016-0131-4.

5. Shan WW. Comparative genomics and host specificity analysis of Ralstonia solanacearum race 4 strain SD54. Shandong Norm Univ. 2014.

6. Prior P, Ailloud F, Dalsing BL, Remenant B, Sanchez B, Allen C. Genomic and proteomic evidence supporting the division of the plant pathogen Ralstonia solanacearum into three species. BMC Genomics. 2016;17(90):1-11. https://doi.org/10.1186/s12864-016-2413-z.

7. Mansfield J, Genin S, Magori S, et al. Top 10 plant pathogenic bacteria in molecular plant pathology. Mol Plant Pathol. 2012;13(6):614-29. https://doi. org/10.1111/j.1364-3703.2012.00804.x.

8. Dalsing BL, Truchon AN, Gonzalez-Orta ET, Milling AS, Allen C. Ralstonia solanacearum uses inorganic nitrogen metabolism for virulence, ATP production, and detoxification in the oxygen-limited host xylem environment. MBio. 2015;6(2):e02471. https://doi.org/10.1128/mBio.02471-14.

9. Cho H, Song ES, Heu S, Baek J, Lee YK, Lee S, et al. Prediction of hostspecific genes by pan-genome analyses of the Korean Ralstonia solanacearum species complex. Front Microbiol. 2019;10:506. https://doi. org/10.3389/fmicb.2019.00506. 
10. Xu J, Pan ZC, Prior P, Xu JS, Zhang Z, Zhang H, et al. Genetic diversity of Ralstonia solanacearum strains from China. Eur J Plant Pathol. 2009;125(4): 641-53. https://doi.org/10.1007/s10658-009-9512-5.

11. Liao BS, Shan ZH, Lei Y, Sun DR. Discussion on the relationship between latent infection by Ralstonia solanaceaum and genetic improvement of resistance to bacteria wilt in peanut. Peanut Sci Technol. 2019;S1:112-5.

12. Luo H, Pandey MK, Khan AW, Wu B, Guo J, Ren X, et al. Next-generation sequencing identified genomic region and diagnostic markers for resistance to bacterial wilt on chromosome B02 in peanut (Arachis hypogaea L.). Plant Biotechnol J. 2019;17(12):2356-69. https://doi.org/10.1111/pbi.13153.

13. Zhang C. Preliminary analysis of resistance molecular Mechanisim to bacterial wilt in peanut. Fujian Agric Forestry Univ. 2013.

14. Schell MA. Control of virulence and pathogenicity genes of Ralstonia Solanacearum by an elaborate sensory network. Annu Rev Phytopathol. 2000;38(1):263-92. https://doi.org/10.1146/annurev.phyto.38.1.263.

15. Genin S, Denny TP. Pathogenomics of the Ralstonia solanacearum species complex. Annu Rev Phytopathol. 2012;50(1):67-89. https://doi.org/10.1146/a nnurev-phyto-081211-173000.

16. Bhatt G, Denny TP. Ralstonia solanacearum iron scavenging by the siderophore staphyloferrin B is controlled by PhcA, the global virulence regulator. J Bacteriol. 2004;186(23):7896-904. https://doi.org/10.1073/pnas. 0509393103

17. Tan X, Qiu H, Li F, Cheng D, Zheng X, Wang B, et al. Complete genome sequence of sequevar 14M ralstonia solanacearum strain HA4-1 reveals novel type III effectors acquired through horizontal gene transfer. Front Microbiol. 2019;10:1893. https://doi.org/10.3389/fmicb.2019.01893.

18. Buttner D, Sheng $\mathrm{YH}$. Type III protein secretion in plant pathogenic bacteria. Plant Physiol. 2009;150(4):1656-64. https://doi.org/10.1104/pp.1 09.139089.

19. Goff SA, Ricke D, Lan TH, Presting G, Wang R, Dunn M, et al. A draft sequence of the rice genome (Oryza sativa L. ssp. japonica). Science. 2002; 296(5565):92-100 https://doi:10.1126/science.1068275.

20. Pavlícek A, Paces J, Clay O, Bernardi G. A compact view of isochores in the draft human genome sequence. FEBS Lett. 2002;511(1-3):165-9 https://doi:1 0.1016/s0014-5793(01)03283-5.

21. Salanoubat M, Genin S, Artiguenave F, Gouzy J, Mangenot S, Arlat M, et al. Genome sequence of the plant pathogen Ralstonia solanacearum. Nat Int Wkly J Sci. 2002;415(6871):497-502. https://doi.org/10.1038/415497a.

22. Chen XQ. Whole genome analysis of Ralstonia solanacearum FJAT-91 and function study on the extracellular polysaccharide. Fujian Agric Forestry Univ. 2018.

23. Berlin K, Koren S, Chin C, Drake JP, Landolin JM, Phillippy AM. Assembling large genomes with single-molecule sequencing and locality-sensitive hashing. Nat Biotechnol. 2015;33(6):623-30. https://doi.org/10.1038/nbt.3238.

24. Chin CS, Alexander DH, Marks P, Klammer AA, Drake J, Heiner C, et al. Nonhybrid, finished microbial genome assemblies from long-read SMRT sequencing data. Nat Methods. 2013;10(6):563-9. https://doi.org/10.1038/ nmeth.2474

25. Peeters N, Carrere S, Anisimova M, Plener L, Cazale AC, Genin S. Repertoire, unified nomenclature and evolution of the type III effector gene set in the Ralstonia solanacearum species complex. BMC Genomics. 2013;14(1):859. https://doi.org/10.1186/1471-2164-14-859.

26. Ochman H, Lawrence JG, Groisman EA. Lateral gene transfer and the nature of bacterial innovation. Nature. 2000;405(6784):299-304. https://doi.org/10.1 038/35012500

27. Gogarten JP, Doolittle WF, Lawrence JG. Prokaryotic evolution in light of gene transfer. Mol Biol Evol. 2002;19(12):2226-38. https://doi.org/10.1093/ oxfordjournals.molbev.a004046.

28. Thomas CM, Nielsen KM. Mechanisms of, and barriers to, horizontal gene transfer between bacteria. Nat Rev Microbiol. 2005;3(9):711-21. https://doi. org/10.1038/nrmicro1234.

29. Wang KK, Remigi P, Anisimova M, Lonjon F, Kars I, Kajava A, et al. Functional assignment to positively selected sites in the core type III effector RipG7 from Ralstonia solanacearum. Mol Plant Pathol. 2016;17(4):553-64. https:// doi.org/10.1111/mpp.12302.

30. Angot A, Peeters N, Lechner E, Vailleau F, Baud C, Gentzbittel L, et al. Ralstonia solanacearum requires F-box-like domain-containing type III effectors to promote disease on several host plants. Pans. 2006;103(39): 14620-5. https://doi.org/10.1073/pnas.0509393103.

31. Sang YY, Wang Y, Ni H, Cazale AC, She YM, Peeters N, et al. The Ralstonia solanacearum type III effector RipAY targets plant redox regulators to suppress immune responses. Mol Plant Pathol. 2018;19(1):129-42. https:// doi.org/10.1111/mpp.12504.

32. Deslandes L, Genin S. Opening the Ralstonia solanacearum type III effector tool box: insights into host cell subversion mechanisms. Curr Opin Plant Biol. 2014;20:110-7. https://doi.org/10.1016/j.pbi.2014.05.002.

33. Nahar K, Matsumoto I, Taguchi F, Inagaki Y, Yamamoto M, Toyoda K, et al. Ralstonia solanacearum type III secretion system effector Rip36 induces a hypersensitive response in the nonhost wild eggplant Solanum torvum. Mol Plant Pathol. 2014;15(3):297-303. https://doi.org/10.1111/mpp.12079.

34. Nakano M, Mukaihara T. The type III effector RipB from Ralstonia solanacearum RS1000 acts as a major avirulence factor in Nicotiana benthamiana and other Nicotiana species. Mol Plant Pathol. 2019;20(9): 1237-51. https://doi.org/10.1111/mpp.12824

35. Guo RL, Zhang G, Cui QN, Feng J, Cheng JF. Regulation, excision and horizontal transfer of genomic islands in bacteria. Microbiol China. 2018; 45(10):2234-42. https://doi.org/10.13344/j.microbiol.china.180005.

36. Canchaya C, Proux C, Fournous G, Bruttin A, Brüssow H. Prophage genomics. Microbiol Mol Biol Rev. 2003;67(2):238-76. https://doi.org/10.112 8/MMBR.67.2.238-276.2003.

37. Kang YP, Lei Y, Wan LY, Huai DX, Yan LY, Liao BS. Study on genetic diversity of bacterium Ralstonia solanacearum in peanut in Yangtze River valley and southern China. J Plant Prot. 2019;46(02):291-7.

38. Faino L, Seidl MF, Datema E, van den Berg GC, Janssen A, Wittenberg AH, et al. Single-molecule real-time sequencing combined with optical mapping yields completely finished fungal genome. Mbio. 2015;6(4):1-11. https://doi. org/10.1128/mBio.00936-15.

39. Fehr A, Gray J, Al E, Luong K, Eid J, Lyle J. Real-time DNA sequencing from single polymerase molecules. Science. 2009;323(5910):133-8. https://doi. org/10.1038/nbt.3238.

40. Chen NS. Using repeatmasker to identify repetitive elements in genomic sequences. Curr Protoc Bioinformatics. 2004:Chapter 4. https://doi.org/10.11 86/1471-2105-11-119.

41. Hyatt D, Chen GL, Locascio PF, Land ML, Larimer FW, Hauser LJ. Prodigal: prokaryotic gene recognition and translation initiation site identification. BMC Bioinformatics. 2010;11(1):119. https://doi.org/10.11 86/1471-2105-11-119.

42. Kent WJ. Blat--the Blast-like alignment tool. Genome Res. 2002;12(4):656-64. https://doi.org/10.1101/gr.229202

43. Birney E, Clamp M, Durbin R. Genewise and genomewise. Genome Res. 2004;14(5):988-95. https://doi.org/10.1101/gr.1865504.

44. Bertelli C, Brinkman F. Improved genomic island predictions with IslandPath-DIMOB. Bioinformatics. 2018;34(13):2161-7. https://doi.org/10.1 093/bioinformatics/bty095.

45. Akhter S, Aziz RK, Edwards RA. PhiSpy: a novel algorithm for finding prophages in bacterial genomes that combines similarity-and composition-based strategies. Nucleic Acids Res. 2012;40(16):e126. https://doi.org/10.1093/nar/gks406.

46. Krzywinski M, Schein J, Birol I, Connors J, Gascoyne R, Horsman D, et al. CIRCOS: an information aesthetic for comparative genomics. Genome Res. 2009;19(9):1639-45. https://doi.org/10.1101/gr.092759.109.

47. Deng YY, Li JQ, Wang SF, Zhu YP, Chen YW, He FC. Integrated nr database in protein annotation system and its localization. Comput Eng. 2006;32(05): 71-3. https://doi.org/10.3969/j.issn.1000-3428.2006.05.026.

48. Tatusov RL, Galperin MY, Natale DA, Koonin EV. The COG database: a tool for genome-scale analysis of protein functions and evolution. Nucleic Acids Res. 2000;28(1):33-6. https://doi.org/10.1093/nar/28.1.33.

49. Michael A, Catherine AB, Judith AB, David B, Heather B, J. MC, et al. Gene ontology: tool for the unification of biology. Nat Genet. 2000;25(1):25-9.

50. Alexa A, Rahnenfuhrer J. topGO: enrichment analysis for gene ontology. $R$ package version 2.42.0; 2020. https://doi.org/10.18129/B9.bioc.topGO.

51. Li L, Christian J, Stoeckert J, David S. OrthoMCL: identification of ortholog groups for eukaryotic genomes. Genome Res. 2003;13(9):2178-89. https:// doi.org/10.1101/gr.1224503.

52. Edgar RC. MUSCLE: multiple sequence alignment with high accuracy and high throughput. Nucleic Acids Res. 2004;32(5):1792-7. https://doi.org/10.1 093/nar/gkh340.

53. Saitou N, Nei M. The neighbor-joining method: a new method for reconstructing phylogenetic trees. Mol Biol Evol. 1987;4(4):406-25. https:// doi.org/10.1093/oxfordjournals.molbev.a040454.

54. Felsenstein J. Confidence limits on phylogenies: an approach using the bootstrap. Evolution. 1985;39(4):783-91. https://doi.org/10.1111/j.1558-5646.1 985.tb00420.x 
55. Zuckerkandl E. Evolutionary divergence and convergence in proteins. Evolving Genes Proteins. 1965:97-166. https://doi.org/10.1016/B978-1-4832-2 734-4.50017-6

56. Kumar S, Stecher G, Tamura K. MEGA7: molecular evolutionary genetics analysis version 7.0 for bigger datasets. Mol Biol Evol. 2016;33(7):1870-4. https://doi.org/10.1093/molbev/msw054.

57. Wang YP, Tang HB, Debarry JD, Tan X, Li JP, Wang XY, et al. MCScanX: a toolkit for detection and evolutionary analysis of gene synteny and collinearity. Nucleic Acids Res. 2012;40(7):e49. https://doi.org/10.1093/nar/ gkr1293.

\section{Publisher's Note}

Springer Nature remains neutral with regard to jurisdictional claims in published maps and institutional affiliations.

Ready to submit your research? Choose BMC and benefit from:

- fast, convenient online submission

- thorough peer review by experienced researchers in your field

- rapid publication on acceptance

- support for research data, including large and complex data types

- gold Open Access which fosters wider collaboration and increased citations

- maximum visibility for your research: over $100 \mathrm{M}$ website views per year

At $\mathrm{BMC}$, research is always in progress.

Learn more biomedcentral.com/submissions 